\title{
Gender Segregation and the Gender Wage Gap: Rising Inequality in Alberta and Saskatchewan
}

\author{
Hussein Al-Zyoud ${ }^{1} \&$ Walid Belassi ${ }^{2}$ \\ ${ }^{1}$ Faculty of Business, Athabasca University, Edmonton, Canada \\ Correspondence: Hussein Al-Zyoud, Faculty of Business, Athabasca University, 1 University Drive Athabasca, \\ AB T9S 3A3, Canada. Tel: 1-780-457-7534. E-mail: husseina@athabascau.ca \\ These Authors contributed equally to this work.
}

Received: November 9, 2016

Accepted: December 14, 2016

Online Published: January 19, 2017

doi:10.5539/ass.v13n2p64

URL: http://dx.doi.org/10.5539/ass.v13n2p64

\begin{abstract}
Canada has made significant historical commitments towards implementing gender equality policies, programs, and legislation after the findings of the Abella Commission were released in 1984 (Abella, 1984). Since then, gender wage gaps have been decreasing in many parts of the country. Two of the Canadian prairie provinces, Alberta and Saskatchewan, have not experienced the same degree of measureable gender equity at the national level, as the other provinces. This paper will therefore examine the gender wage gaps in these two provinces. To investigate gender wage gaps in Alberta and Saskatchewan, the paper examines two industries in each of the two provinces that are fundamentally different in terms of the gender of their workforce composition. In particular, the study compares the oil and gas industry, which is predominantly male dominant, with the predominantly female dominant healthcare and social assistance industry in order to discover whether wage gaps are industry specific, and can be explained by the size of worker-affiliated organizations in particular provinces and industries. The study also investigates the effects of years of job tenure on gender wage gaps. The results demonstrate that, in both provinces, regardless of industry, the size of the organization proves significant in explaining gender wage gaps, while years of tenure are insignificant.
\end{abstract}

Keywords: Alberta, Gender wage gap, job tenure, occupations, Saskatchewan

\section{Introduction}

It is necessary to approach the subject of inequality in the labour force with the notion of intersectionality, since inequality is affected by a myriad of complex variables other than gender, race, and age. The intersection of geography, occupation, size of community, education, work tenure, physical strength, and family structure have been shown to significantly impact women in the labour force (Blau \& Kahn, 2007; Cotter, Hermsen, \& Vanneman, 2003; Drolet \& Mumford, 2012). Occupational segregation is crucial in determining economic gender inequality (Yavorsky, Cohen, \& Qian, 2016). Two main questions have dominated previous research in the area of inequality in the labour market:

(1) Is there an observable pattern of segregation in the employment market? (Tam, 1997; England, 2010; Pan, 2015)

(2) Why is there a gap in wages between men and women? (Cotter, Hermsen, \& Vanneman, 2003; Blau \& Kahn, 2007; Drolet \& Mumford, 2012).

The first question focuses on the distribution of employees by personal characteristics across industries and levels of employment. The second question deals specifically with gender and wage differences linking the characteristic of gender to economic factors.

The history of women in the labour market details how the reality of women's employment has changed over the past century. These changes have also affected a shift in social attitudes regarding the role of women in the labour market. The most significant changes in women's equity have occurred over the last 30 years as increasing numbers of women, including married women, remain in the labour force fairly continuously, even when they have young children at home. Canadian Provinces have made historic commitments to implementing gender equality policies, programs and legislation after the publication of the 1984 Abella Report from the Commission on Employment Equity. The commission report identified education, industry choice, native status, 
disability, and demographic factors as factors all having a negative impact on employment equity for women in Canada. However, shifts in taxation policies, changes to local social services programs and the economic downturn of the 1990s lead the attempts to decrease gender wage gaps (Al-Zyoud \& Leblanc, 2016).

Despite the increasing number of women of all ages entering and staying in the labour market and a general acceptance in society of women in the labour force across all occupational categories, there remains a significant gap in wages and career mobility for women. Ample research supports the fact that an observable gender wage gap persists and that gender segregation directly affects this gender wage gap (Blau et al., 2007; England, 2010; Pan, 2015). A myriad of policies, legislation, jurisprudence, and scholarly theories have attempted to address the issue of segregation and gender differences in employment. Previous research has focused primarily on the issue of variations in gender wage gaps (McInturff, 2013; Weiner, 2014; Lahey, 2015). However, it remains unclear as to why there are greater gaps in gender equity across two of the Canadian prairie provinces; Alberta and Saskatchewan, compared with the rest of the country. It is hypothesized that unique factors of industry, population composition and economic growth in the prairie provinces support the higher gendered wage gaps. Two dominant areas of employment in Alberta and Saskatchewan are the sectors of healthcare and social assistance and resource development (mining and oil and gas extraction).

The first research question how occupational gender distribution affects wage equity in the labour market. The first research question will be connected with the second question of why there are noticeable correlated gender wage gaps. This study focus on gendered wage gaps and occupational segregation of males and females, who are employed full time with a University degree in two dominant industries across the provinces of Alberta and Saskatchewan. This research takes into account the factors of education level, type of industry and years of experience on the job to explain wage differences between genders.

Despite growing gender wage gaps in Alberta and Saskatchewan little formal research has been conducted on this issue (McInturff, 2013). This study primarily contributes to the current literature by examining wage gap differences between men and women which may be explained by the size and type of industry and by job tenures, since jobs in different industries provide different remuneration. Thus, if female workers are concentrated in particular sectors that consistently pay less than other sectors, this may explain these wage gaps.

The remainder of the article is structured as follows: the following section, section 2, provides background information about the Alberta and Saskatchewan regions in respect to unique factors which impact employment equity. A review of the relevant literature on the issue of gender in employment is described in section 3 . Section 4 explains research methodology and the resulting data used in the study. Empirical findings are presented in section 5 , and the conclusions of the study are presented in section 6 .

\section{Factors Which Uniquely Impact Employment in the Prairies}

The Canadian Prairie Provinces span over $2000 \mathrm{~km}^{2}$ and are divided into three Provinces; Alberta, Manitoba, and Saskatchewan. The resource-rich regions have long served as a crucial lynchpin in the national economy" (Statistics Canada, 2015). Over the past 20 years, there has been strong economic growth in all Provinces. Surging oil, manufacturing and agriculture prices have produced increasing business investment and corporate profits. Increases in employment opportunities in Saskatchewan and Alberta have been dominated by the sectors of health care, education, mining-quarrying-oil and gas extraction. In examining the relationship between gender and employment inequity in both Provinces, unique characteristics of each region will be detailed, specifically the distribution of employees across occupational categories, gender composition of the population and economic growth rates.

\subsection{Occupational Categories}

In Canada and across the globe, industries which provide employment are inherently segregated, with most occupations dominated by one gender or the other (OECD, 2011). In Canada, the gender distribution of employees by occupational sector varies widely across the country. In 2015, Statistics Canada reported that women are most likely to be employed in sales and service occupations $(27.1 \%)$; business, finance and administration occupations (24.6\%); and occupations in education, law, and social/health care services (16.8\%) of the labour forces. Health and education industries have typically been recognized as women's work (Statistics Canada, 2015). In contrast, goods-producing industries are typically characterized as male occupations and are dominated by male employees, for instance, men employed in the goods-producing and a transportation sector is $25.5 \%$ of the labour forces (Statistics Canada, 2015).

As for the Provinces of Alberta and Saskatchewan, Table 1 depicts average female employment in two major sectors in both Provinces during the period of 1997-2015. Of note is that a comparison of specific occupations 
over time is challenging due to varying National Occupational Classifications.

Table 1. Average Female Employment in Two Major Sectors in the Provinces of Alberta (AB) and Saskatchewan (SK) (Note 1)

\begin{tabular}{cccc}
\hline Provinces & Years & $\begin{array}{c}\text { Forestry, fishing, mining, quarrying, oil and } \\
\text { gas (average annual employment) }\end{array}$ & $\begin{array}{c}\text { Health care and social } \\
\text { assistance(average annual employment) }\end{array}$ \\
\hline \multirow{4}{*}{$\mathrm{AB}$} & $1997-2001$ & 87330 & 144996 \\
& $2002-2006$ & 116667 & 167030 \\
& $2007-2011$ & 147175 & 204768 \\
& $2012-15$ & 171175 & 242304 \\
\multirow{4}{*}{ SK } & $1997-2001$ & 15110 & 51511 \\
& $2002-2006$ & 18305 & 58245 \\
& $2007-2011$ & 25133 & 65908 \\
& $2012-2015$ & 27000 & 74256 \\
\hline
\end{tabular}

Source: Authors' calculations based on Statistics Canada, Labour Force Survey, 1997-2015.

\subsection{Population Characteristics}

The gender composition of the population in the Provinces of Alberta and Saskatchewan is unique from the rest of the country in both the labour force participation rates of women workers and the growth of the population. During the last 20 years, the national labour force has increased by an average of $26 \%$ while the labour forces of Alberta and Saskatchewan have increased by $57 \%$ and $15 \%$ respectively (Statistics Canada, Table 282-0087) In addition, despite the fact that the increase in the number of women in the labour force also demonstrates a comparable tendency with the national $25 \%$ increase, the Alberta female labour force has increased at a more significant level and exceeds the national level by 56\%. However, the Saskatchewan female labour force demonstrates only a moderate growth rate and has increased by only 13\% during the years of 1997-2015. Finally, Statistics Canada report indicates over $7 \%$ of employees who work in the provinces were live in another Province (Statistics Canada, 2016).

\subsection{Economic Growth in Alberta and Saskatchewan Regions over the Past 20 Years}

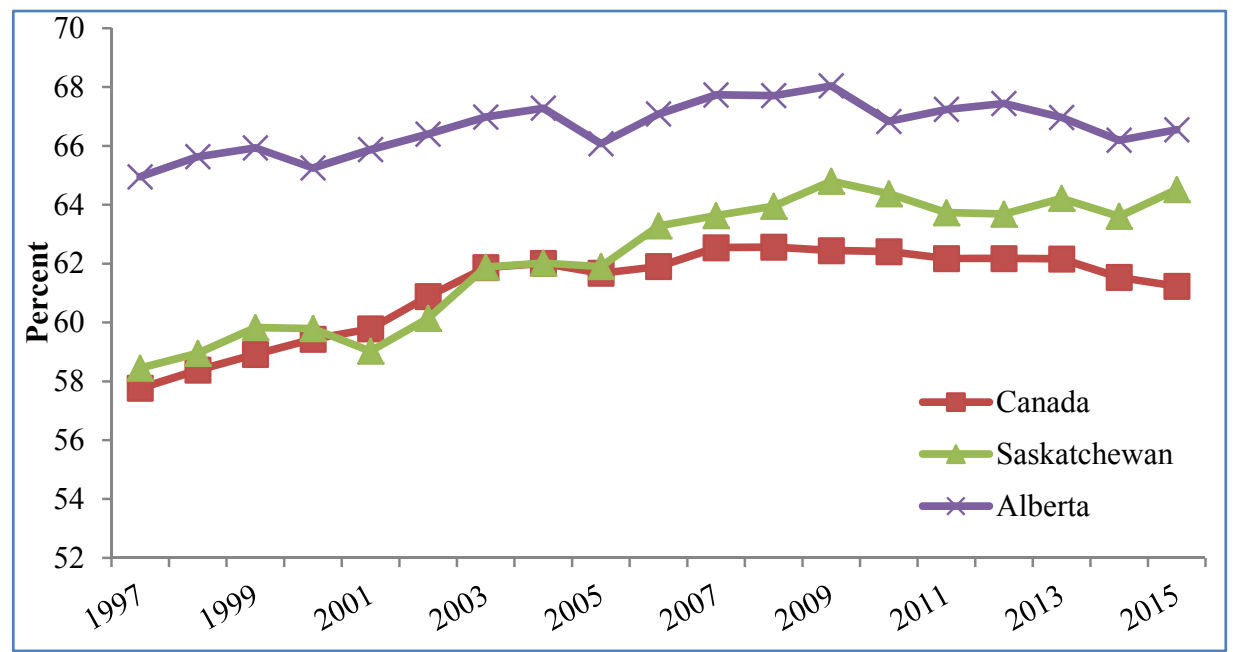

Figure 1. Labour Force Participation Rates for All Women Aged 15 and Over- Canada, Alberta, and Saskatchewan

Sources: Authors' calculations based on Statistics Canada Labour Force Survey-1997-2015.

According to Statistics Canada reports on job vacancies and wages, the Canadian prairie provinces had the highest job vacancy rate at $2.8 \%$ (on average) in the fourth quarter of 2015. Alberta and British Columbia accounted for $31.0 \%$ of all job vacancies, with $44.1 \%$ of all vacancies in male dominated occupations. This reflects the persistent economic growth the region had experienced. The National Household Survey (NHS) of May 2011 indicated that Alberta had the highest employment rates in Canada at 69.0\%, with Saskatchewan at 
65.1\% (Statistics Canada, 2011). Together the Prairies provinces represented the highest employment rates nationally and showed persistent and dramatic growth not seen in the rest of the nation.

Figure 1 depicts how Albertan women have had a relatively higher rate of labour force participation than the rest of the country. Saskatchewan women's labour force participation rate caught up to the national level and has exceeded it since the mid-2000s. Conversely, Eastern Provinces have much lower job vacancy rates, with Quebec posting the lowest rate of $1.6 \%$ (job bank, 2016.). However, despite persistent growth and employment opportunities in both Provinces, there remain significant gendered wage gaps. In fact, recent studies indicate that a gender wage ratio of 0.73 in Alberta for 2014 does exist (Graff-McRae, 2016).

Figure 1 also depicts how labour force participation rates of all women in Canada aged 15 and over and in Alberta and Saskatchewan rose over the study period (1997 to 2015). The Alberta female labour force participation rates exceed the national level, and Saskatchewan women's labour market participation rates have dramatically increased since 2005 .

\section{Literature Review}

The fact that men continue to earn more than women for equal work is not a new issue, but does require frequent re-examination of the factors which contribute to gender inequity (Drolet, 2011). The issue of gender in employment is deeply rooted in organizational attitudes surrounding employment. Three primary economic theories; gender devaluation theory, the specialized human capital hypothesis and gendered organizational theory have evolved to explain why there is an observable pattern of gender segregation in the labour market (Tam, 1997; Tomaskovic, Devey, \& Skaggs, 2002). All three of these theories detail the effects of cultural bias against women in relation to labour market considerations. Researchers have identified elements inherent in all theories of gender in employment: (1) Tenure and skills were once a primary factor in explaining why there was a gender wage gap, but current research indicates that women have closed the wage gap in these terms of these factors. (2) The issue of gendered job segregation has been shown to have an impact on the gender wage gap based on at least one labour factor across the entire labour market. (3) Size of the firm has revealed a positive impact on the gender wage gap. Particularly with regard to how legislation and changing social attitudes about gender have impacted gender in employment. It has been noted that the remaining wage inequity, after accounting for known gender preferences and demographic factors, may reflect discrimination.

Previous research has generally identified how wage disparity and occupational segregation negatively impacts women, even after accounting for a wide range of measurable characteristics (Sorensen, 1990; Tam, 1997; England, 2010). The factors which impact the gender wage gap continue to be an essential concept of research not only because of the changing landscape of equity, but, also because of the evidence which indicates persistent gender discrimination in employment (Munasinghe, Reif \& Henriques). The factors which relate to gender discrimination are crucial components which are essential in the development of employment equity legislation.

The gender devaluation theory suggests that women's work is paid less due to systemic attitudes about women. A persistent cultural bias against women is one of the fundamental concepts in the theory of discrimination (Tam, 1997). According to Magnusson's recent study (2016), gender wage gaps in the highly prestigious occupations of medical professionals in Sweden revealed some of the practical impacts of this cultural bias against women in employment. Brynin and Perales (2016) suggest that there is a need for future research to distinguish between women's work (those occupations which are dominated by women and have historically been paid less as a result) and women's skills (the training, education and experience women of certain age groups hold).

The devaluation theory states that all workers in a specific industry which is predominated by women or viewed as 'women's' work are paid less compared to male-dominated industries (Jacobs \& England, 1993; Mandel, 2013; Magnusson, 2016; Tam, 1997) suggested that industry segregation and not discrimination is the determining factor in wage inequality. Tam's contention was supported by the research of Blau and Kahn, 2003 and England, 2002. On the other hand, Brynin et al. (2016) explained that occupational gender segregation is visible within industries as much as it is between industries. These studies have consistently revealed that industries with the highest level of occupational segregation displayed the highest percentage of gender wage gaps.

The specialized human capital hypothesis contends that apparent gender wage gaps are merely a difference in specialized occupation specific, industry specific or regionally determined training. It was once thought that low-level education requirements combined with specialized on-the-job training programs would enable young women to compete for the opportunities in the employment market (OECD, 1998). However, gender differences in education have yet to explain overall gender wage gaps and research demonstrates that gender differences in years of schooling favour women (Blau et al., 2007). Simply put, scholars who argue the specialized human 
capital hypothesis assert that the traditional division of labour may disadvantage women due to gender differences in skill and experience (Blau et al., 2007).

Blau et al., 2007 examine persistent wage gaps between men and women in connection to other social attitudes regarding education and training. Their study focuses on full-time workers and adjusts for gender differences in hours worked, since women are more likely than men to work part-time. Their study concludes that less-educated women have narrowed the pay gap with less-educated men and highly educated women have narrowed the pay gap with highly educated men. However, women continue to earn considerably less than men on average. Despite the narrowing of gender wage gaps across education levels and age, there remain distinct and persistent wage gaps based on social attitudes (Magnusson, 2015; Pan, 2015).

As in this study, which examines specific occupation groups in specific industries and within specified regions of Canada, Magnusson (2015) recognizes the advantage of focusing on a specific occupational group. The study contends that a primary cause of gendered wage gaps is occupational segregation, which begins with choice of subjects studied at University. However, even among those who choose the same subjects and occupation, there are noticeable gendered wage gaps as early as one year after graduation. Magnusson contends that this may be attributed to within-occupation gender segregation. Men appear to choose specialty fields that are dominated by men rather than fields dominated by women. This may be attributed to a difference in social values applied to men and women in professional occupations. One seemingly significant contention in Magnusson's research is the correlation between family status, gender, and wages. Numerous previous studies support the idea that marriage and children are considered a plus for male employees while the same family status among women results in a negative effect on occupational progress and/or wage equity (Magnusson, 2015).

This idea of self-segregation is supported by Magnusson's (2015) study on the gender wage gap among Swedish doctors. The gendered wage gap is observable in Sweden as in other Western and European societies, particularly among University graduates in highly specialized occupations. Magnusson's study focused on the 18-65 age group in the public and private sectors. The dependent variable used was the natural logarithm of monthly wages reported by employers for full-time/full-year workers. Thus the potential for differences in productivity would have limited effect on the data. Age was used as a proxy for time spent in the labour market since more effective measures such as work experience were not available. Finally, specialization level in occupational hierarchy (management over non-management), and family status were identified as relevant coefficients in the ordinary least squares (OLS) regression.

The foundational components of the gendered organizational theory contend that gender inequality is essential to the capitalist commitment to productivity and market primacy. The theory posits that gender inequality is a fundamental value at the core of organizations based on social expectations, values and beliefs around labour distribution (Clegg, 1981; Mills, 2016; Pierce, 1995). In a model of occupational tipping and segregation, Pan (2015) tests whether male employees prefer working in the same occupations as females and the role of women in employment. This study suggests that the history of occupational gender segregation is foundational to understanding persistent gendered wage gaps and occupational segregation. Pan asserts that even small differences in gender composition in an occupation can have large impacts over time, assuming employers are non-discriminatory when choosing employees. Essentially, social attitudes toward working with the opposite gender are the primarily deciding factor in occupational segregation. As a result of male preferences, as more women enter an occupation, more men leave for better pay and benefits. This opens employment opportunities up to which more women apply and are employed. Employers then respond by lowering wages because they can employ female labour for lower pay and benefits. Pan points out in her conclusion that the tipping point for men is lower in regions where there are greater "sexist attitudes toward the appropriate role of women" (Pan, 2015).

\section{Methodology}

To investigate gender wage gaps in Alberta and Saskatchewan, this study compares a male dominant industry (oil and gas) with a female dominant sector (healthcare and social assistance). The objective of the study is to examine whether or not wage gaps are industry specific. More importantly, the study is carried out to discover whether or not higher wages paid to male employees is limited to male dominated industries, as well as to examine whether this corresponds to wage gaps in female dominated industries. Our underlying assumption is that if wage gaps favour men in male dominated industries and women in female dominated industries, then wage gaps may not be due to discrimination, but may prove the existence of gender preferences in particular industries, where such industries reward the dominant gender.

\subsection{Data Collection}

In this study, we focus on two independent variables that have proved by the literature to be influential in 
determining wages in general, and wage gaps in particular. Our study focuses on the effects of job tenure and size of organization, i.e. the effects of difference in tenure and the number of employees working in medium and large-sized organizations on gender wage gaps.

Data regarding average job tenure (in years) and the number of employees working in medium and large organizations in each of the two industries and by gender (in Alberta and Saskatchewan)was obtained for the period 1997-2015 from Statistics Canada's Labour Force Survey monthly public use micro data. In measuring wage gaps, we use employee average hourly wage data for the period 1997 - 2015. Average hourly wages are also obtained from Statistics Canada's Labour Force Surveys.

\subsection{Research Model and Assumptions}

To study the effect of job tenure and number of employees working in different sizes of organizations, we use multiple regression analysis. Our hypothesized model is:

$$
\mathrm{WG}=\beta_{0}+\beta_{1} \mathrm{DT}+\beta_{2} \mathrm{DML}+\mathrm{e}
$$

Where,

- WG is gender wage gap

- DT is the difference in average tenure (between males and females) in years of service

- DML is the difference (between males and females) in the number of employees working in medium and large organizations (in thousands)

- $\mathrm{X}_{0}$ is the intercept

- $\mathrm{e}$ is the error term

We test the significance of our independent variables in the oil and gas and healthcare and social assistance industries in Alberta and Saskatchewan in the following section.

Our assumption is that employees' wages are positively proportionate to job tenure. Employees with more job tenure tend to be paid more than employees with less job tenure. We expect the difference in job tenure to be an influential factor in determining wage gaps. Similarly, we expect a positive relationship between wages and the size of the organization. For example, medium and large organizations should tend to pay their employees more than small sized organizations. If a particular gender (male or female) is working mainly in small organizations, their hourly wages should tend to be less. A wage gap would then be due to the size of organization a particular gender group works for, rather than possible gender discrimination.

\section{Discussion}

Table 2. Average Hourly Wage by Gender and Province

\begin{tabular}{|c|c|c|c|c|}
\hline & \multicolumn{4}{|c|}{ Average Hourly Wage } \\
\hline & \multicolumn{2}{|c|}{ Oil \& Gas } & \multicolumn{2}{|c|}{ Health Care \& SA } \\
\hline & Males & Females & Males & Females \\
\hline \multirow{2}{*}{ Alberta } & 32.7 & 27.1 & 25.0 & 22.5 \\
\hline & \multicolumn{2}{|c|}{$\mathrm{t}=2.53, \mathrm{p}=.016$} & \multicolumn{2}{|c|}{$\mathrm{t}=1.45, \mathrm{p}=.15$} \\
\hline \multirow{2}{*}{ Saskatchewan } & 27.8 & 22.5 & 23.3 & 21.4 \\
\hline & \multicolumn{2}{|c|}{$\mathrm{t}=2.86 . p=.007$} & \multicolumn{2}{|c|}{$\mathrm{t}=1.20 . \mathrm{p}=.23$} \\
\hline
\end{tabular}

As indicated in Table 2, average hourly wages for males are higher than those of their female counterparts. In the oil and gas industry in Alberta, males are paid, on average, $\$ 32.7$ per hour, while their female counterparts are paid \$27.1 an hour, yielding a gender wage gap differential of $17 \%$. The difference in hourly wage is significant at the .05 level $(\mathrm{t}=2.53$, $\mathrm{p}$-value $=.016)$.

In Alberta's healthcare sector, males are still paid higher (on average) than their female counterparts. While males are paid an average hourly rate of $\$ 25$, their female counterparts are paid $\$ 22.5$, yielding a wage gap differential of $10 \%$. The wage gap is statistically insignificant $(\mathrm{t}=1.45$, $\mathrm{p}$-value $=0.15)$.

Saskatchewan shows near-identical results to Alberta. The average hourly wage of $\$ 27.8$ in the oil and gas industry for males is significantly higher than that of females (\$22.5), which leads to a $19 \%$ gender wage gap differential. The difference in average hourly wages is significant at the .005 level $(\mathrm{t}=2.86$, $\mathrm{p}$-value $=.007)$. In the healthcare and social assistance sector, men are paid $\$ 23.25$ on average, while females are paid $\$ 21.36$ on 
average, an $8.1 \%$ gender wage gap differential. The difference in average hourly pay between males and females is insignificant $(\mathrm{t}=1.20 ; \mathrm{p}$-value $=0.24)$.

In summary, Table 2 indicates that males tend to consistently earn disproportionately higher wages than their female counterparts in the oil and gas industry. In healthcare and social assistance, however, males do not consistently earn disproportionately higher wages than their female counterparts.

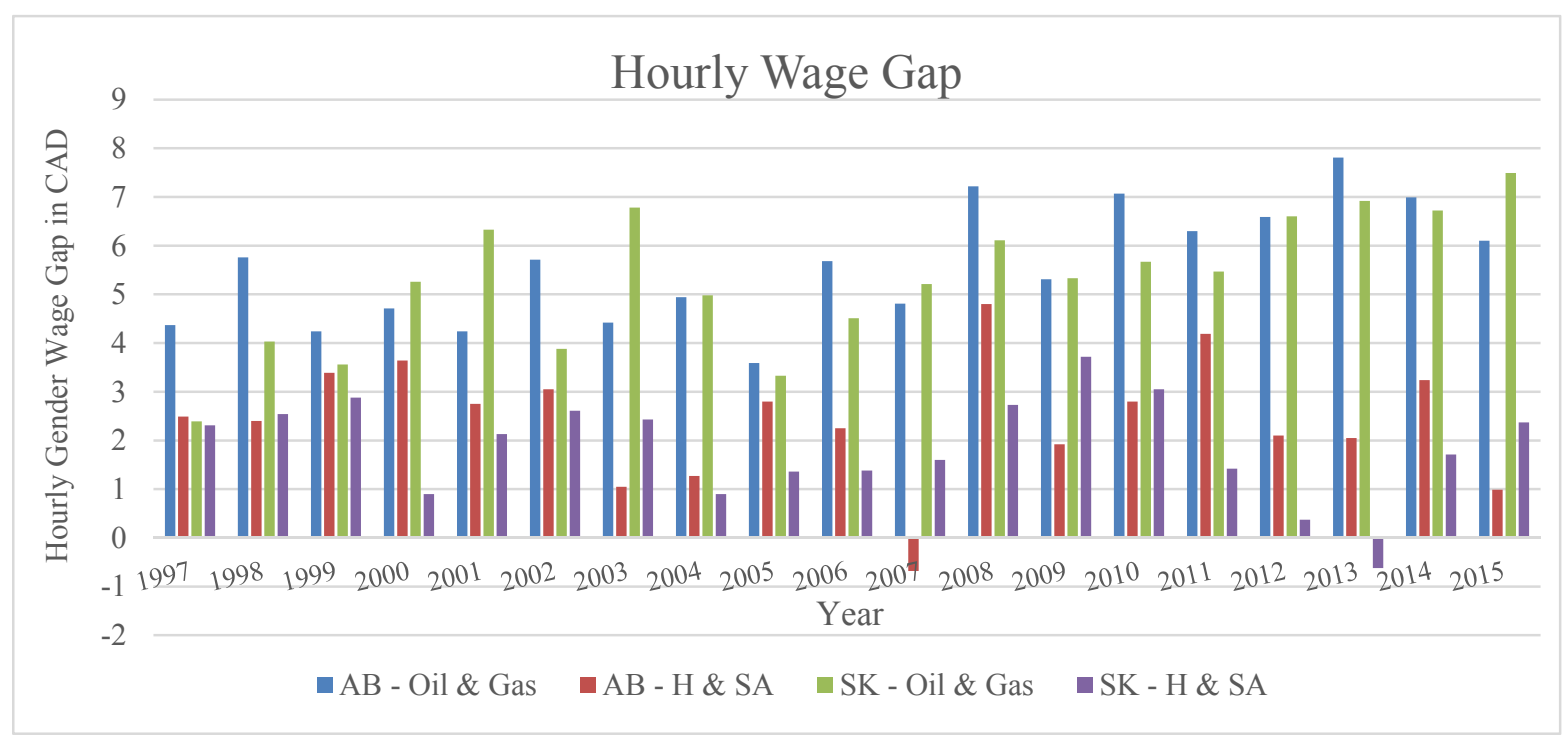

Figure 2. Gender Wage Gap by Province and Industry during the Period of $1997-2015$
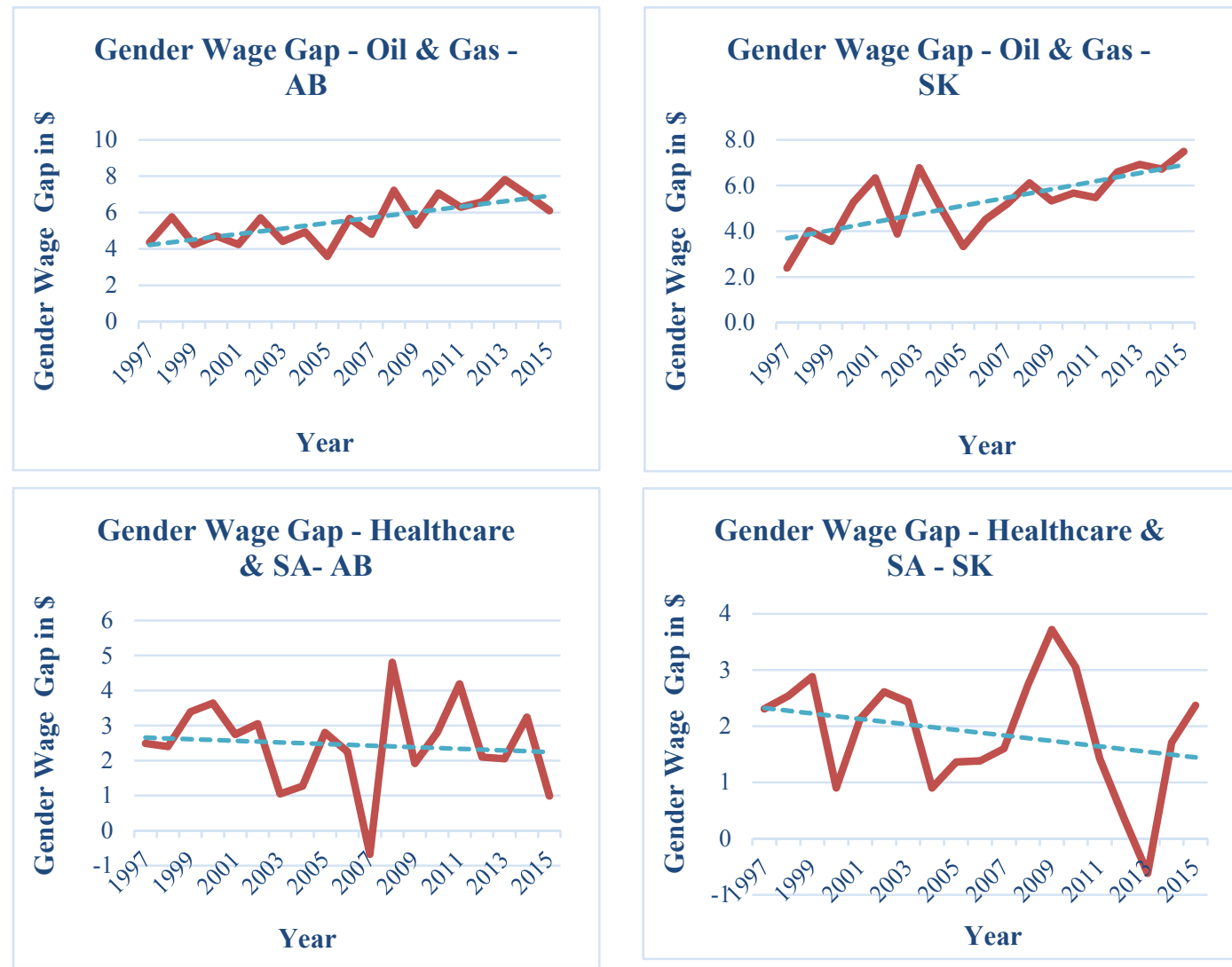

Figure 3. Trends of Gender Wage Gaps by Industry and Province

Figure 3 above depicts how gender wage gaps in both Provinces have widened annually in the oil and gas industry (more so in Saskatchewan). The figure also depicts how annual gender wage gaps are narrowing slightly 
in the healthcare and social assistance industry.

As indicated in Table 3 below, in the oil and gas industry in Alberta, average job tenure for male employees is 6.54 years, as opposed to 5.80 years for their female counterparts. Differences in job tenure are significant at the .01 level. Similarly, average job tenure for males in the healthcare and social assistance sector is higher than average job tenure of their female counterparts (8.41 and 7.69 years, respectively). This difference is also significant at the .01 level.

The Saskatchewan data in Table 3indicates similar results, except for an insignificant difference in job tenure effects in the healthcare and social assistance sector. In the oil and gas industry, male employees have significantly more job tenure than their female counterparts (9.22 years vs. 8.15). Difference in job tenure is significant at the .05 level.

Table 3. Average Male \& Female Job Tenure (in Years) By Province and Industry

\begin{tabular}{|c|c|c|c|c|c|c|c|}
\hline \multicolumn{4}{|c|}{ Alberta } & \multicolumn{4}{|c|}{ Saskatchewan } \\
\hline \multicolumn{2}{|c|}{ Oil \& Gas } & \multicolumn{2}{|c|}{ Healthcare and SA } & \multicolumn{2}{|c|}{ Oil \& Gas } & \multicolumn{2}{|c|}{ Healthcare and SA } \\
\hline Males & Females & Males & Females & Males & Females & Males & Females \\
\hline 6.54 & 5.8 & 8.41 & 7.69 & 9.22 & 8.15 & 9.97 & 9.75 \\
\hline t Stat & 4.1 & t Stat & 4.08 & t Stat & 2.69 & t Stat & 0.94 \\
\hline $\begin{array}{l}\mathrm{P}(\mathrm{T}<=\mathrm{t}) \\
\text { two-tail }\end{array}$ & 0.0002 & $\begin{array}{l}\mathrm{P}(\mathrm{T}<=\mathrm{t}) \\
\text { two-tail }\end{array}$ & 0.0002 & $\begin{array}{l}\mathrm{P}(\mathrm{T}<=\mathrm{t}) \\
\text { two-tail }\end{array}$ & 0.0109 & $\begin{array}{l}\mathrm{P}(\mathrm{T}<=\mathrm{t}) \\
\text { two-tail }\end{array}$ & 0.3544 \\
\hline
\end{tabular}

In terms of gender segregation, the results provide a profile of employed workers in Alberta and Saskatchewan in both the oil and gas and healthcare and social assistance industries. As indicated in Table 4 below, the oil and gas industries in Alberta and Saskatchewan are heavily dominated by men (68622 and 12731 male employees respectively). Conversely, the healthcare and social assistance sector is heavily dominated by females, both in Alberta and Saskatchewan (104895 and 35062 respectively).

While the number of employees working in medium and large sized organizations in Alberta in the oil and gas industry is greater than the number of their female counterparts, the percentage of female employees working in medium and large size organizations $(58 \%)$ is higher than the percentage of their male counterparts $(45 \%)$ that are working in medium and large size organizations. Similarly, while the number of female employees working in medium and large sized organizations in the healthcare and social assistance sector (104895 in Alberta and 35062 in Saskatchewan) is greater than the number of males (18948 in Alberta and 9107 in Saskatchewan), the percentage of men, compared to total employees working in the industry, working in medium and large organizations, is higher than their female counterparts. The same phenomenon applies to Saskatchewan.

Table 4. Female and Male Employees vs. the Size of the Organization

\begin{tabular}{cccccc}
\hline Number of Employees & Male & $\begin{array}{c}\text { Organizations with } \\
\text { Less than } 99 \\
\text { Employees }\end{array}$ & $\begin{array}{c}\text { Organizations with } \\
\text { 100 or More } \\
\text { Employees }\end{array}$ & $\begin{array}{c}\text { Total Number } \\
\text { of Employees }\end{array}$ & $\begin{array}{c}\text { \% Working in } \\
\text { Med. \& Large } \\
\text { Companies }\end{array}$ \\
\hline \multirow{2}{*}{ AB - Oil \& Gas } & Female & 87493 & 31130 & 68622 & $45 \%$ \\
& Male & 8593 & 12221 & 21138 & $58 \%$ \\
AB - Healthcare \& SA & Female & 62547 & 10355 & 18948 & $55 \%$ \\
SK - Oil \& Gas & Male & 6848 & 42348 & 104895 & $40 \%$ \\
& Female & 1224 & 5883 & 12732 & $46 \%$ \\
SK - Healthcare \& SA & Male & 3029 & 1153 & 2377 & $49 \%$ \\
\hline
\end{tabular}

Sources: Authors' calculations based on Statistics Canada, Labour Force Survey, 1997-2015

\subsection{Multiple Regression Analysis}

We tested our proposed regression model in both the oil and gas industry and the healthcare and social assistance sector, in Alberta and Saskatchewan. The intercepts, coefficients, t-values, Adjusted R Square and significance F values are displayed in Table 5. 
As indicated in Table 5, the models for the oil and gas industry proved to be significant in Alberta $(\mathrm{F}=.012)$ and Saskatchewan $(\mathrm{F}=0.010)$. In both Provinces, the number (in thousands) of employees working in medium and large organizations proved to be the significant determinant of gender wage gap (p-values 0.004 and 0.003 , respectively). The adjusted $\mathrm{R}^{2}$ values indicate that the regression models explain $35.6 \%$ and $36.6 \%$ of the variation in gender gap in Alberta and Saskatchewan, respectively.

Table 5. Regression Models

\begin{tabular}{|c|c|c|c|c|c|}
\hline & Constant & DT & DML & AdjustedR $^{2}$ & Significance $\mathrm{F}$ \\
\hline AB Oil\& Gas - Model 1 & 2.601 & $\begin{array}{l}0.0231 \\
(0.073)\end{array}$ & $\begin{array}{c}0.157 \\
(3.383)^{* * *}\end{array}$ & 0.356 & $0.012 * *$ \\
\hline AB Oil\& Gas - Model 2 & 2.632 & N/A & $\begin{array}{c}0.157 \\
(3.563)^{* * *}\end{array}$ & 0.394 & $0.002 * * *$ \\
\hline AB Healthcare \& SA & 9.283 & $\begin{array}{l}-0.6233 \\
(-1.256)\end{array}$ & $\begin{array}{c}0.200 \\
(1.78)^{*}\end{array}$ & 0.084 & 0.193 \\
\hline SK Oil\& Gas - Model 1 & 1.387 & $\begin{array}{l}-0.0403 \\
(-0.167)\end{array}$ & $\begin{array}{c}0.245 \\
(3.533)^{* * *}\end{array}$ & 0.366 & $0.010 * * *$ \\
\hline SK Oil\& Gas - Model 2 & 2.591 & N/A & $\begin{array}{c}0.572 \\
(4.501)^{* * *}\end{array}$ & 0.515 & $0.0003 * * *$ \\
\hline SK Healthcare \& SA & 3.391 & $\begin{array}{l}-0.3495 \\
(-0.871)\end{array}$ & $\begin{array}{c}0.103 \\
(0.413)\end{array}$ & -0.0737 & 0.689 \\
\hline
\end{tabular}

***, $* *$, and $*$ indicate $1 \%, 5 \%$, and $10 \%$ significance

Job tenure proves to be an insignificant determinant of wage gaps in the oil and gas industry, both in Alberta and Saskatchewan ( $\mathrm{p}$ values 0.943 for Alberta and 0.869 for Saskatchewan). Due to its insignificant effect, we eliminated job tenure from the suggested regression model. Adjusted $\mathrm{R}^{2}$ increased for the oil and gas industry in both Provinces, indicating the higher explanatory power of the adjusted models (models 2) for both Provinces. For Alberta, adjusted $\mathrm{R}^{2}$ increased to $39.4 \%$, while in Saskatchewan adjusted $\mathrm{R}^{2}$ increased to $51.5 \%$. This indicates that the difference in the number of people working in medium and large size organizations (between males and females), alone, explains between 39.4\% (in Alberta) and 51\% (in Saskatchewan) of the variation in the gender wage gap in those two provinces.

The two regression models for activity in the healthcare and social assistance sectors proved to be insignificant (Significance F 0.193 for Alberta and 0.678 for Saskatchewan), indicating that the variables included in the models do not significantly influence gender wage gaps in Alberta or Saskatchewan. Adjusted $\mathrm{R}^{2}$ for both models are unsurprisingly low (.084 for Alberta and -0.037 for Saskatchewan), indicating the inability of the models to explain the variation in gender wage gaps in the healthcare and social assistance sectors in Alberta and Saskatchewan. However, gender segregation is a strong determinant of gender wage gap in the oil and gas industry, both in Alberta and Saskatchewan.

As for the healthcare and social assistance sector, the regression models for both provinces proved to be insignificant. In other words, both variables included in the models (job tenure and the difference in number of employees working in medium and large size organizations) do not affect (at least significantly) gender wage gaps. Despite the overall insignificance of both models, the low adjusted $\mathrm{R}^{2}$ and the insignificant $\mathrm{p}$-values for the included variables, the comparison between the results obtained from the healthcare and social assistance models and those of the oil and gas industries reveals a number of facts that are worth further investigation.

The oil and gas industry, both in Alberta and Saskatchewan, is mostly male dominant. In Alberta, 76 percent of the employees in the oil and gas industry are males, while only 24 percent of the employees are females. Similarly, in Saskatchewan, 89 percent of the employees working in the oil and gas industry are males, while only 11 percent of the employees are females.

In both of these male dominant industries, the higher number (see Table 4) of male (dominating gender in terms of percentage) employees working in medium and large organizations translated into a wage gap that favours that gender.

When comparing these results to the healthcare and social assistance sectors, the results are astounding. Contrary to the oil and gas industry, the healthcare and social assistance sector is female dominant both in Alberta and 
Saskatchewan. Female employees represent $85 \%$ of the workforce in Alberta (104,896 employees), while males represent only 15 percent $(18,948)$. In the healthcare and social assistance sector in Saskatchewan, female employees represent $86 \%$ of the total workforce; while male employees in Saskatchewan represent only 14 percent of the total workforce.

The number of female employees working in organizations with 100 and more employees, both in Alberta and Saskatchewan, is higher than that of the male employees. Unlike the oil and gas industry, however, the higher number of female employees (dominant gender) working in medium and large organizations did not translate into higher wages for the dominant gender. In fact, gender wage gaps remained in favour of, yet not significantly higher, for male employees in healthcare and social assistance, a female dominated industry.

\section{Conclusion}

Our study demonstrates that gender wage gaps in Alberta and Saskatchewan do exist, especially in the oil and gas industry, where the wage gap seems to be increasing. Wage gaps can mainly be explained by the size of the organizations where a dominant gender works. In both the healthcare and social assistance and oil and gas industries, the size of the organization reveals almost $52 \%$ of the variation in the gender wage gap. However, contrary to the study's expectations, job tenure had an insignificant effect on gender wage gaps in both industries. When comparing the results of both industries, in either province, it is clear that gender wage gaps always favour males, regardless of industry specific circumstances, and whether or not the industry is dominated by males or females. The study indicates that potential biases towards male employees, when it comes to wages, may exist. Therefore, a recommendation is made that future researchers examine the implications of gender related wage gaps in various sectors of the economy for specific industries rather than broad groups of industries.

\section{References}

Al-Zyoud, H., \& Leblanc, C. (2016). The Trend and Dynamics of Income Inequality in Alberta (Unpublished manuscript) Faculty of Business, Athabasca University, Alberta, Canada.

Blau, F. D., \& Kahn, L. M. (2003).Understanding international differences in the gender pay gap. Journal of Labor Economics, 21(1), 106-144. doi:10.1086/344125

Blau, F. D., \& Kahn, L. M. (2007). The gender pay gap: Have women gone as far as they can? Academy of Management Perspectives, 21(1), 7-23. doi:10.5465/amp.2007.24286161

Brynin, M., \& Perales, F. (2016). Gender Wage Inequality: The De-gendering of the Occupational Structure. European Sociological Review, 32(1), 162-174. doi:10.1093/esr/jcv092

Clegg, S. (1981). Organization and control. Administrative Science Quarterly, 26(4), 545. doi:10.2307/2392339

Cotter, D. A., Hermsen, J. M., \&Vanneman, R. (2003). The effects of occupational gender segregation across race. The Sociological Quarterly, 44(1), 17-36. doi:10.1525/tsq.2003.44.1.17

Drolet, M. (2011). The persistent gap: New evidence on the Canadian gender wage gap. SSRN Electronic Journal. doi:10.2139/ssrn.310600

Drolet, M., \& Mumford, K. (2011). The gender pay gap for private-sector employees in Canada and Britain. British Journal of Industrial Relations, 50(3), 529-553. doi:10.1111/j.1467-8543.2011.00868.x

England, P. (2010). The gender revolution: Uneven and stalled. Gender \& Society, 24(2), 149-166. doi: $10.1177 / 0891243210361475$

Graff-McRae, R. Parkland Institute. (2016). Why should Alberta implement pay equity legislation? Because it's 2016. Alberta. Retrieved November 1, 2016, from Alberta, http://behindthenumbers.ca/2016/03/15/whyshould-alberta-implement-pay-equity-legislation-because-its-2016/.

Gunderson, M. (2006). Viewpoint: Male-female wage differentials: How can that be? Canadian Journal of Economics/Revue canadienne d'<html_ent glyph="@eacute;" ascii="e"/>conomique, 39(1), 1-21. doi:10.1111/j.0008-4085.2006.00336.x

Jacobs, J. A., \& England, P. (1993). Comparable worth: Theories and evidence. Contemporary Sociology, 22(5), 728. doi: $10.2307 / 2074656$

Job Market Trends and News. (2016). Retrieved June 3, 2016, from www.jobbank.gc.ca/LMI_bulletin.do

Judge Rosalie Silberman Abella. (1984). Report of the Royal Commission on Equity in Employment. Canada; Canadian Publishing Services, Ottawa.

Magnusson, C. (2015). The gender wage gap in highly prestigious occupations: A case study of Swedish medical 
doctors. Work, Employment \& Society, 30(1), 40-58. doi:10.1177/0950017015590760

Mandel, H. (2013). Up the down staircase: Women's upward mobility and the wage penalty for occupational Feminization, 1970-2007. Social Forces, 91(4), 1183-1207. doi:10.1093/sf/sot018

McCullough, J. J. (n. d.). The Canadian Prairies J.J.'s Complete Guide to Canada. Retrieved from http://www.thecanadaguide.com/the-prairies

McInturff, K. (2013). Closing Canada's gender gap: Year 2240 here we come. Behind the Numbers, Canadian Centre for Policy Alternatives. Retrieved May 15, 2016, from http://https://www.policyalternatives.ca/ sites/default/files/uploads/publications/National\%20Office/2013/04/Closing_Canadas_Gender_Gap_0.pdf

Mills, A. (2016). Mills, A. J. (1992). Organization, gender and culture. In A J. Mills, \& P. Tancred (Eds.), Gendering organizational analysis (pp. 93-111). Newbury park, CA.: Sage. Retrieved from http://www.aca demia.edu/227830/Mills_A.J._1992_Organization_Gender_and_Culture_._In_Gendering_Organizational_ Analysis_edited_by_A.J._Mills_and_P._Tancred_Sheriff_pp.93-111._Newbury_Park_CA._Sage

Munasinghe, L., Reif, T., \& Henriques, A. (2008). Gender gap in wage returns to job tenure and experience. Labour Economics, 15(6), 1296-1316. doi:10.1016/j.labeco.2007.12.003

Organization for Economic Co-operation and Development (OECD). (2011). Divided We Stand: Why Inequality Keeps Rising. Retrieved from http://www.oecd.org/els/social/inequality

Pan, J. (2015). Gender segregation in occupations: The role of tipping and social interactions. Journal of Labor Economics, 33(2), 365-408. doi:10.1086/678518

Payne, L. (2002). Gendered Jobs and Gendered Workers: Barriers to Gender Equality in Gendered Organizations. University of Guelph, Excellence in Canadian Work-Family Research.

Pierce, J. L. (1995). Gender Trials: Emotional Lives in Contemporary Law Firms. Los Angeles: University of California Press.

Sorensen, E. (1990). The crowding hypothesis and comparable worth. The Journal of Human Resources, 25(1), 55. doi:10.2307/145727

Statistics Canada. (2011). 2011 national household survey: Data tables. Retrieved June 17, 2016, from https://www12.statcan.gc.ca/nhs-enm/2011/dp-pd/dt-td/Ap-eng.cfm? Catalogue number; 99-012-X2011060.

Statistics Canada. (2015). 2015 national household survey: Data tables. Retrieved June 16, 2016, from http://www5.statcan.gc.ca/cansim/a47\#F10

Statistics Canada. (2015). Portrait of Canada's Labour Force. Retrieved June 1, 2016, from http://www12.statcan.gc.ca/nhs-enm/2011/as-sa/99-012-x/99-012-x2011002-eng.pdf

Statistics Canada. (2016). Portrait of Canada's Labour Force. Retrieved June 1, 2016, from http://www12.statcan.gc.ca/nhs-enm/2011/as-sa/99-012-x/99-012-x2011002-eng.pdf

Tam, T. (1997). Sex segregation and occupational gender inequality in the United States: Devaluation or specialized training? American Journal of Sociology, 102(6), 1652-1692. doi:10.1086/231129

The Future of Female Dominated Occupations. Organization for Economic Co-operation and Development (OECD). DOI:10.1787/9789264163690-en.

Tomaskovic-DeveyDon, \& Skaggs, S. (2002). Sex segregation, labor process organization, and gender earnings inequality. American Journal of Sociology, 108(1), 102-128. doi:10.1086/344214

Yavorsky, J. E., Cohen, P. N., \& Qian, Y. (2016). Man up, man down: Race-ethnicity and the hierarchy of men in female-dominated work. The Sociological Quarterly, 57(4), 733-758. doi:10.1111/tsq.1215

Note

Note 1. Average annual female employment in forestry, fishing, mining, quarrying, oil and gas, health care and social assistance

\section{Copyrights}

Copyright for this article is retained by the author(s), with first publication rights granted to the journal.

This is an open-access article distributed under the terms and conditions of the Creative Commons Attribution license (http://creativecommons.org/licenses/by/4.0/). 